\title{
Een rookvrije omgeving in het belang van het kind
}

\author{
Timor Faber · Leonieke J. Breunis · Jasper V. Been · Brigit Toebes
}

Published online: 29 January 2020

(c) The Author(s) 2020

Samenvatting Kinderen die worden blootgesteld aan tabaksrook hebben vaker (levenslange) gezondheidsproblemen. Toch ademen nog veel kinderen in Nederland tabaksrook in. Rookvrije wetgeving is een krachtig middel om kinderen te beschermen tegen tabaksrook. Hierdoor worden minder baby's te vroeg geboren en minder kinderen in het ziekenhuis opgenomen voor luchtweginfecties of ernstige astma-aanvallen. Onderzoek toont aan dat hoe meer plekken onder deze wetgeving vallen, hoe groter het gezondheidseffect is. Internationale juridische standaarden, waar Nederland aan gebonden is, nopen tot het invoeren van verder strekkende rookvrije wetgeving.

Trefwoorden rechten van het kind - rookvrije omgevingen $\cdot$ rookvrije wetgeving $\cdot$ preventie

\section{Tabaksrook en de gezondheid van kinderen}

Tabaksrook heeft allerlei nadelige, maar vermijdbare, effecten op de gezondheid van het (nog ongeboren)

\section{T. Faber ·. V. Been}

Afdeling Maatschappelijke Gezondheidszorg, Universitair Medisch Centrum Rotterdam, Rotterdam, Nederland

\section{B. Toebes $(\bowtie)$}

Global Health Law Groningen Research Centre, Afdeling Transboundary Legal Studies, Faculteit Rechtsgeleerdheid, Rijksuniversiteit Groningen, Groningen, Nederland b.c.a.toebes@rug.nl

T. Faber $\cdot$ J. V. Been

Afdeling Kindergeneeskunde, divisie Neonatologie, Erasmus MC - Sophia Kinderziekenhuis, Universitair Medisch Centrum Rotterdam, Rotterdam, Nederland

\section{J. Breunis $\cdot$ J. V. Been}

Afdeling Verloskunde en Gynaecologie, Erasmus MC Sophia Kinderziekenhuis, Universitair Medisch Centrum Rotterdam, Rotterdam, Nederland kind. Roken tijdens de zwangerschap verhoogt het risico op ongunstige zwangerschapsuitkomsten, zoals perinatale sterfte, vroeggeboorte, groeivertraging, en aangeboren afwijkingen. Ook na de geboorte is blootstelling aan tabaksrook ongezond. Kinderen die regelmatig meeroken hebben een verhoogd risico op wiegendood, luchtweginfecties en astma. Op de langere termijn is er meer risico op astma, ontwikkelingsachterstand en gedragsproblemen. Kinderen van rokende ouders gaan ook vaker later zelf roken. Volwassenen die als kind zijn blootgesteld hebben vaker luchtwegproblemen.

Roken - en het bijkomstige meeroken - is de nummer één vermijdbare oorzaak van ziekte en vroegtijdige sterfte wereldwijd. Bijna de helft van alle kinderen wereldwijd wordt regelmatig blootgesteld aan tabaksrook en jaarlijks overlijden hierdoor naar schatting 56.000 kinderen onder de 10 jaar. In Nederland werd in $20172 \%$ van de 0 - tot 4 -jarigen, $8 \%$ van de 4 - tot 12 -jarigen en $18 \%$ van de 12 - tot 16 -jarigen regelmatig blootgesteld aan tabaksrook binnenshuis.

Kinderen zijn bijzonder kwetsbaar voor de schadelijke effecten van tabaksrook omdat zij nog in ontwikkeling zijn en hun eigen blootstelling niet kunnen beïnvloeden. Het is daarom essentieel dat kinderen actief beschermd worden, bijvoorbeeld via wetgeving gericht op een rookvrije omgeving ('rookvrije wetgeving') [1]. De vraag of en zo ja in hoeverre de Nederlandse overheid rookvrije wetgeving verder moet uitbreiden staat centraal in deze bijdrage.

\section{Rookvrije wetgeving is effectief}

Uit veelvuldig onderzoek blijkt dat de invoering van wetgeving gericht op rookvrije publieke binnenruimten gunstig is voor de volksgezondheid: zo daalt het aantal ziekenhuisopnamen voor hartinfarcten, luchtwegklachten en beroertes aanzienlijk. Deze gezond- 
heidswinst is groter naarmate de wetgeving meer publieke plaatsen omvat.

Ook kinderen hebben expliciet baat bij rookvrije wetgeving. In een systematische analyse is het verband tussen invoering van door de Wereldgezondheidsorganisatie (WHO) geadviseerde tabaksontmoedigingsmaatregelen en de gezondheid van (ongeboren) kinderen uitvoerig onderzocht [2]. Samenvoeging van data van meer dan 25 miljoen geboorten en ruim 2 miljoen ziekenhuisopnamen van kinderen liet zien dat er na het invoeren van rookvrije wetgeving een afname met $4 \%$ was in vroeggeboorten $(95 \%$-betrouwbaarheidsinterval (BI) $-6-1$ ), een afname met $10 \%$ in ziekenhuisopnamen voor astma-aanvallen $(95 \%$ BI -17-3) en een afname met $18 \%$ in ziekenhuisopnamen voor lagere luchtweginfecties $(95 \%$-BI -33-4) [2]. Ook hier ging de meest omvangrijke wetgeving consistent gepaard met de grootste gezondheidswinst.

Rookvrije wetgeving wordt in het algemeen goed ontvangen door de maatschappij, inclusief rokers, en lijkt daarnaast ook zeer kosteneffectief. Niet alleen worden hierdoor kinderen minder blootgesteld aan tabaksrook in openbare ruimten, maar ook het roken en meeroken tijdens de zwangerschap nemen duidelijk af. Daarnaast maken steeds meer mensen ook hun eigen huis rookvrij na invoering van rookvrije wetgeving. Dit is belangrijk, aangezien kinderen thuis het meest worden blootgesteld aan tabaksrook.

$\mathrm{Nu}$ de voordelen van rookvrije openbare binnenruimten uitgebreid zijn aangetoond, worden op steeds meer plekken in de wereld ook openbare buitenruimten rookvrij gemaakt. Denk aan plekken waar veel kinderen komen, zoals schoolterreinen, speeltuinen, pretparken en sportclubs, maar ook stranden en terrassen. Waar deze locaties in Nederland vooralsnog vaak rookvrij werden op lokaal initiatief, voorziet het Nationaal Preventieakkoord nu ook in landelijke afspraken: met ingang van 2020 moeten kinderboerderijen, schoolterreinen en kinderopvanglocaties rookvrij zijn, en vanaf 2025 ook speeltuinen, sportverenigingen en ziekenhuisterreinen.

\section{Internationale verplichtingen inzake rookvrije wetgeving}

Twee internationale kaders zijn van wezenlijk belang bij de vormgeving van nationale tabakswetgeving: het WHO Kaderverdrag inzake tabaksontmoediging (FCTC, 2003) en mensenrechten, in het bijzonder het Internationaal Verdrag inzake de Rechten van het Kind (IVRK, 1989).

Het FCTC omvat minimumvereisten waar landen aan moeten voldoen, waaronder de bescherming tegen meeroken in Artikel 8 FCTC. Deze bepaling verplicht lidstaten juridische en administratieve maatregelen te nemen ter bescherming tegen meeroken op 'binnen gebouwen gelegen werkplekken, het openbaar vervoer, binnen openbare gebouwen en, naar gelang van het geval, op andere openbare plaatsen'. De implementatierichtlijnen van het FCTC bepalen dat een 'openbare plaats' een breed begrip is dat alle plekken omvat die toegankelijk zijn voor publiek. Overheden dienen daarnaast de 'meest effectieve' bescherming in te stellen voor deels of niet afgesloten openbare plaatsen. Zij moeten vooral letten op plekken die zowel werkplek als woon- en verblijfplaats zijn (bijvoorbeeld gevangenissen, zorginstellingen of verzorgingshuizen).

Betreffende de privésfeer adviseren de richtlijnen om nationale campagnes te organiseren die waarschuwen voor de gevaren van meeroken op plekken waarvoor wetgeving niet haalbaar of wenselijk is. Een afname van de blootstelling aan tabaksrook in de thuisomgeving valt onder een achttal proces- en resultaatsindicatoren gericht op de mate van implementatie en handhaving van de verplichtingen uit Artikel 8 FCTC.

Een tweede internationaal kader vormen de mensenrechten, elementaire bestaansrechten die ieder mens toekomen. Kinderen zijn rechthebbenden onder de algemene mensenrechtenverdragen, maar kunnen zich vooral beroepen op het Kinderrechtenverdrag (IVRK). Hoewel het IVRK tabaksontmoediging niet expliciet noemt, is een aantal rechten uit het verdrag van belang om kinderen tegen tabaksgerelateerde gezondheids- en ontwikkelingsschade te beschermen [3]. Voor jonge kinderen zijn vooral de Artikelen 3, 6 en 24 (met aanvulling van 27) IVRK belangrijk (tab. 1).

Artikel 3 IVRK omvat een van de kernbeginselen van het IVRK: het verplicht overheden het 'belang van het kind' als primaire afweging mee te wegen 'bij alle maatregelen betreffende kinderen, ongeacht of deze worden genomen door openbare of particulieren instellingen voor maatschappelijk welzijn of door rechterlijke instanties, bestuurlijke autoriteiten of wetgevende lichamen'. Dit betekent dus dat het belang van het kind moet worden meegewogen in gezondheidsbeleid, waaronder tabaksontmoediging en daarmee ook het instellen van rookvrije wetgeving $[3,4]$. Gebeurt dit niet door middel van bijvoorbeeld een impactanalyse, dan zou dat een schending van Artikel 3 IVRK kunnen opleveren.

Op basis van artikel 24 IVRK hebben kinderen het recht op een zo goed mogelijke gezondheid. Volgens het VN-Kinderrechtencomité valt tabaksontmoediging direct binnen de reikwijdte van het recht op gezondheid. Interessant is dat het comité er daarbij bij landen specifiek op aandringt om rookvrije leefomgevingen te creëren. Volgens het comité is een gezonde leefomgeving voor kinderen ook een rookvrije thuisomgeving. Het comité stelt verder in het licht van Artikel 6 IVRK, dat het recht op leven, overleven en ontwikkeling waarborgt dat de gezondheid van ouders en verzorgers een belangrijk aspect is van de gezondheid van kinderen. 


\section{Forum}

Tabel 1 Overzicht van internationale en lokale verplichtingen met betrekking tot een rookvrije omgeving

\begin{tabular}{|c|c|c|c|}
\hline & $\begin{array}{l}\text { WHO-Kaderverdrag inzake de tabaks- } \\
\text { ontmoediging }(\text { FCTC) }\end{array}$ & Mensenrechten & Situatie in Nederland \\
\hline \multicolumn{4}{|c|}{ Algemene/integrale verplichting } \\
\hline & \multirow[t]{2}{*}{ N.v.t. } & $\begin{array}{l}\text { Artikel } 3 \text { IVRK } K^{b} \text { belang van het kind als } \\
\text { eerste overweging toepassen in gezond- } \\
\text { heidsbeleid (bijvoorbeeld door middel van } \\
\text { impactanalyse) }\end{array}$ & $\begin{array}{l}\text { De regering omarmt de Rookvrije Generatie in } \\
\text { het regeerakkoord van Rutte III; dit is overigens } \\
\text { geen impactanalyse }\end{array}$ \\
\hline & & $\begin{array}{l}\text { Artikel } 6 \text { en } 24 \text { IVRK } \text { : Preventieve gezond- } \\
\text { heidszorg realiseren met aandacht voor } \\
\text { alle fasen van ontwikkeling en gezondheid } \\
\text { en gezondheidsgerelateerd gedrag van } \\
\text { onder anderen ouders }\end{array}$ & \\
\hline \multicolumn{4}{|c|}{ Verplichting ten aanzien van specifieke plekken } \\
\hline $\begin{array}{l}\text { Afgesloten openbare } \\
\text { plekken }\end{array}$ & Artikel 8 FCTC : verplicht & \multirow[t]{11}{*}{$\begin{array}{l}\text { Indirect door bestendiging van het FCTC } \\
\text { door het IVRK-Comitéb }\end{array}$} & Artikel 10 Tabaks- en rookwarenwet \\
\hline Openbaar vervoer & Artikel 8 FCTC : verplicht & & Artikel 10 Tabaks- en rookwarenwet \\
\hline $\begin{array}{l}\text { Andere openbare } \\
\text { plekken, waaronder } \\
\text { deels afgesloten plek- } \\
\text { ken en de buitenlucht }\end{array}$ & $\begin{array}{l}\text { Implementatierichtlijn Artikel } 8 \text { FCTC }{ }^{\text {a: }} \\
\text { uitbreiding op grond van wetenschap- } \\
\text { pelijk bewijs effectiviteit bescher- } \\
\text { mingsmaatregel (bijvoorbeeld rookvrije } \\
\text { wetgeving) }\end{array}$ & & $\begin{array}{l}\text { Lokale initiatieven zoals het aanpassen van de } \\
\text { Algemene Plaatselijke Verordening in Groningen }\end{array}$ \\
\hline a Scholen & $\begin{array}{l}\text { Implementatierichtlijn Artikel } 8 \text { FCTC } \\
\text { uitbreiding op grond van } \\
\text { wetenschappelijk bewijs effectiviteit } \\
\text { beschermingsmaatregel (bijvoorbeeld } \\
\text { rookvrije wetgeving) }\end{array}$ & & $\begin{array}{l}\text { Artikel } 10 \text { Tabaks- en rookwarenwet regelt } \\
\text { dat scholen en andere opvanglocaties rookvrij } \\
\text { zijn. Per de zomer van } 2020 \text { zijn echter ook } \\
\text { alle terreinen van onderwijsinstellingen en } \\
\text { kinderopvanglocaties rookvrij }\end{array}$ \\
\hline \multicolumn{3}{|l|}{ b Pretparken } & \\
\hline c Recreatiegebieden & & & $\begin{array}{l}\text { Uit het Nationaal Preventie Akkoord blijkt dat } \\
\text { in } 2020 \text { alle kinderboerderijlocaties volledig } \\
\text { rookvrij dienen te zijn }\end{array}$ \\
\hline$d$ Sportclubs & & & $\begin{array}{l}\text { Artikel } 10 \text { Tabaks- en rookwarenwet (gebouw); } \\
\text { Nationaal Preventie Akkoord in 2020: } 2500 \\
\text { sportverenigingen volledig rookvrij (dus ook het } \\
\text { hele terrein) }\end{array}$ \\
\hline Werkplekken & Artikel 8 FCTC $C^{\mathrm{a}}$ : verplicht & & Artikel 10 Tabaks- en rookwarenwet \\
\hline $\begin{array}{l}\text { Gevangenissen, } \\
\text { zorginstellingen en } \\
\text { verpleegtehuizen } \\
\text { (en vergelijkbare } \\
\text { instellingen) }\end{array}$ & $\begin{array}{l}\text { Implementatierichtlijn Artikel } 8 \text { FCTC } \\
\text { bescherming als zijnde werkplek }\end{array}$ & & $\begin{array}{l}\text { Artikel } 10 \text { Tabaks- en rookwarenwet (Artikel } \\
6.3 \text { Tabaks- en Rookwarenbesluit, rookruimten } \\
\text { zijn toegestaan) }\end{array}$ \\
\hline Horecagelegenheden & Artikel 8 FCTC $C^{\mathrm{a}}$ : verplicht & & Artikel 10 Tabaks- en rookwarenwet \\
\hline Auto's & $\begin{array}{l}\text { Implementatierichtlijn Artikel } 8 \text { FCTC } \\
\text { nationale campagnes wanneer rook- } \\
\text { vrije wetgeving in de privésfeer niet } \\
\text { passend en gerechtvaardigd is in } \\
\text { nationale wetgeving }\end{array}$ & & $\begin{array}{l}\text { Past niet binnen het huidige uitgangspunt van } \\
\text { de Tabaks- en rookwarenwet }\end{array}$ \\
\hline $\begin{array}{l}\text { Private omgeving } \\
\text { (woning, tuinen en } \\
\text { balkon) }\end{array}$ & $\begin{array}{l}\text { Implementatierichtlijn Artikel } 8 \text { FCTC } \\
\text { nationale campagnes wanneer rook- } \\
\text { vrije wetgeving in de privésfeer niet } \\
\text { passend en gerechtvaardigd is in } \\
\text { nationale wetgeving }\end{array}$ & $\begin{array}{l}\text { IVRK-Comitéc op grond van Artikel } 24 \text { en } \\
27 \text { IVRK } K^{\circ} \text { Aanmoediging om rookvrije } \\
\text { thuisomgeving te creëren }\end{array}$ & \\
\hline
\end{tabular}

\section{De situatie in Nederland: waar gaat en moet het heen?}

De Nederlandse Tabaks- en rookwarenwet en het Tabaks- en rookwarenbesluit reguleren de rookvrije binnenruimten in Nederland. Overheidsgebouwen, zorg-, culturele, sport- en onderwijsinstellingen, werkplekken, horeca en het openbaar vervoer moeten onder meer rookvrij zijn. Nederland heeft internationale kritiek gekregen op de gebrekkige invoering en handhaving van deze wetgeving. De naleving van rookvrije wetgeving in Nederland is lange tijd veel slechter geweest dan in voorbeeldlanden als het Verenigd Koninkrijk. Tegen de voorschriften van de FCTC in werden uitzonderingen toegestaan, bijvoorbeeld voor de kleine cafés, en door het toelaten van interne 
rookruimten in publieke instellingen. In vergelijking met andere Europese landen bevindt Nederland zich daarmee in de middenmoot als het gaat om rookvrije wetgeving.

Het uitbreiden van rookvrije omgevingen is in Nederland in beweging. Zo zijn er verschillende lokale initiatieven om bijvoorbeeld openbare buitenruimten rookvrij te maken, zoals in Groningen en Rotterdam. Het Nationaal Preventie Akkoord spreekt een duidelijke ambitie uit om onder andere schoolterreinen, kinderboerderijen, speeltuinen en sportparken rookvrij te maken.

Sommige landen breiden rookvrije wetgeving ook uit richting de privésfeer, bijvoorbeeld in de vorm van rookvrije auto's. Gezien de duidelijke samenhang tussen meeroken en gezondheidsproblemen bij kinderen en de extreem hoge concentraties van gevaarlijke stoffen uit tabaksrook wanneer er in de auto wordt gerookt, ligt het in de lijn der verwachting dat de gezondheid van kinderen baat heeft bij dergelijke wetgeving, mits adequaat gehandhaafd. Een verbod op roken in de auto staat daarnaast in verhouding tot bestaande wetgeving die verplicht om een gordel om te doen of die verbiedt om te bellen tijdens het rijden. De eerste onderzoeken laten een gemengd beeld zien als het gaat om de effecten van dergelijke wetgeving op rookblootstelling en gezondheid, mogelijk samenhangend met de duidelijke uitdagingen als het gaat om handhaving van dergelijke wetgeving $[5,6]$.

$\mathrm{Al}$ met al pleiten wij ervoor dat Nederland het uitgangspunt van de Tabakswet herziet in het licht van internationale standaarden en ervaringen elders. Gezien de gevoeligheid van kinderen voor de negatieve effecten van tabaksrook en hun onvermogen om hun eigen blootstelling te reguleren is het noodzakelijk om verdergaande regulering van roken in drukbezochte buitenruimten en niet-publieke binnenruimten te overwegen. Deze verbreding strookt met het FCTC en in het bijzonder het Kinderrechtenverdrag.

Uiteraard rijst de vraag wat het draagvlak voor dergelijke wetgeving is. Uit recent onderzoek in Nederland blijkt dat zeven op de tien de Nederlanders vinden dat de overheid meer maatregelen moet nemen om kinderen tegen tabaksrook te beschermen [7]. Dit percentage is de afgelopen jaren duidelijk toegenomen en vooral voor rookvrije schoolterreinen, kinderboerderijen, speeltuinen, kinderdagverblijven en sportterreinen is er veel draagvlak. Ook onder Nederlandse jongeren is er veel steun voor de invoering van rookvrije auto's (90\%) en schoolpleinen (65\%) [8]. In landen als Engeland, waar roken in de auto in het bijzijn van minderjarigen is verboden, steunt de meerderheid van de volwassenen, onder wie rokers, dergelijke maatregelen. Een ruime meerderheid pleit zelfs voor een algeheel verbod op roken in de auto, hetgeen mogelijk de handhaving zou kunnen vergemakkelijken.

\section{Conclusie}

Er is een maatschappelijke verschuiving gaande in Nederland rond de aanpak van roken en meeroken. Er zijn gezondheidswetenschappelijke en juridische gronden om verdergaande rookvrije wetgeving in te voeren. Rookvrije wetgeving verbetert de gezondheid van kinderen en internationale juridische standaarden sluiten aan bij deze wetenschappelijke bevindingen. De FCTC-richtlijnen moedigen lidstaten aan om in hun nationale wetgeving een zo ruim mogelijk begrip van openbare plaats te hanteren. Het Kinderrechtenverdrag verplicht overheden om het belang van het kind in acht te nemen bij de aanname van wetgeving en beleid dat kinderen treft, zoals bij het instellen van rookvrije omgevingen. Het VN-Kinderrechtencomité dringt er daarnaast op aan ook rookvrije thuisomgevingen te creëren. Met inbegrip van de verschillende haken en ogen die aan een dergelijke uitbreiding zitten, zal Nederland verdergaande maatregelen op grond van bindende internationale standaarden serieus moeten overwegen.

Open Access This article is licensed under a Creative Commons Attribution 4.0 International License, which permits use, sharing, adaptation, distribution and reproduction in any medium or format, as long as you give appropriate credit to the original author(s) and the source, provide a link to the Creative Commons licence, and indicate if changes were made. The images or other third party material in this article are included in the article's Creative Commons licence, unless indicated otherwise in a credit line to the material. If material is not included in the article's Creative Commons licence and your intended use is not permitted by statutory regulation or exceeds the permitted use, you will need to obtain permission directly from the copyright holder. To view a copy of this licence, visit http://creativecommons.org/licenses/by/4.0/.

\section{Literatuur}

1. Been JV, Sheikh A. Tobacco control policies in relation to child health and perinatal health outcomes. Arch Dis Child. 2018;103(9):817-9.

2. Faber T, Kumar A, Mackenbach JP, et al. Effect of tobacco control policies on perinatal and child health: a systematic review and meta-analysis. Lancet Public Health. 2017;2(9):e420-37.

3. Toebes B, Gispen ME, Been JV, et al. A missing voice: the human rights of children to a tobacco-free environment. Tob Control. 2018;27(1):3-5.

4. Gispen MEC, Hesselman MM, Toebes B. De rol en potentie van het internationaal recht in het reguleren van ongezond gedrag: ongezond voedsel, alcohol en tabaksontmoediging. In: Keirse ALM, Kool RSB, Ortlep R, redactie. Ongezond en (on)geoorloofd. Publiek- en privaatrecht \& legale maar gezondheidsbedreigende producten en diensten. Den Haag: Boom Juridische Uitgevers; 2018.

5. Patel M, Thai CL, Meng YY, et al. Smoke-free car legislation and student exposure to smoking. Pediatrics. 2018;141(1):S40-50. 


\section{Forum}

6. Faber T, Mizani MA, Sheikh A, et al. Investigating the effect of England's smoke-free private vehicle regulation on changes in tobacco smoke exposure and respiratory disease in children: a quasi-experimental study. Lancet Public Health. 2019;4(12):e607-17.

7. KWF. Driekwart Nederlanders pleit voor actief rookvrij beleid. 2019. https://www.kwf.nl/over-kwf/pages/

pb-driekwart-nederlanders- pleit-voor-actief-rookvrijbeleid.aspx. Geraadpleegd op: 27 mei 2019.

8. Schreuders M, Lagerweij NA, Putte B van den, Kunst AE. To what extent and why adolescents do or do not support future tobacco control measures: a multimethod study in the Netherlands. Tob Control. 2017;27(5):596-9. 